\title{
Neuromodulacija kao izbor liječenja kod djeteta s neurogenim mokraćnim mjehurom - prikaz slučaja
}

1 Darija Dobrić

1 Andrea Cvitković Roić

1 Vesna Kumanović

1 Marinela Škunca

1 Poliklinika za dječje bolesti Helena

\section{Sažetak}

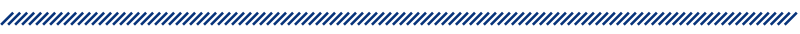

Uvod. Neurogeni mokraćni mjehur nastaje zbog prirođenog ili stečenog oštećenja inervacije donjega mokraćnog sustava. lako se incidencija prirođenih anomalija kralježnice smanjuje, one i dalje predstavljaju najvažniji uzrok neurogenog mjehura, koji nastaje u oko $95 \%$ ove djece. Neuromodulacija kao fizioterapijska intervencija ima važnu ulogu u rehabilitaciji djece s neurogenim mokraćnim mjehurom.

Cilj ovog rada bio je prikazati slučaj djeteta s neurogenim mokraćnim mjehurom uslijed spine bifide i mogućnosti neuromodulacije u rehabilitaciji ove djece.

Razrada. Prikazan je slučaj djeteta s neurogenim mokraćnim mjehurom nastalim kao posljedica spine bifide occulte s retencijom urina nakon operacijskog zahvata. Specifična fizioterapijska procjena na početku ukazuje na smanjenu količinu urina u mokraćnom mjehuru uz nepotpuno pražnjenje, gubitak osjeta punoće mjehura i cjelodnevni bijeg urina. Fizioterapijska intervencija uključivala je svakodnevni tretman neuromodulacije prema zadanom protokolu u trajanju od 20 do $30 \mathrm{~min}$. Djetetovi su roditelji educirani o nastavku provođenja terapije u mjestu stanovanja uz nabavku uređaja.
Zaključak. Dijagnoza neurogenoga mokraćnog mjehura zahtijeva multidisciplinarni pristup u svrhu postizanja što bolje kvalitete života djeteta. Neuromodulacija kao oblik terapijskog liječenja ima dokazanu pozitivnu učinkovitost kod brojnih poremećaja mokrenja, ne zahtijeva posebnu pripremu djeteta, jednostavna je za primjenu, a rezultati ovise individualno o svakom djetetu.

Ključne riječi: neurogeni mokraćni mjehur, neuromodulacija, fizioterapija

Datum primitka: 26.09.2017.

Datum prihvaćanja: 30.11.2017.

DOI: $10.24141 / 1 / 3 / 2 / 10$

Adresa za dopisivanje:

Darija Dobrić

Poliklinika za dječje bolesti Helena,

Kneza Branimira 71, Zagreb, Hrvatska

Tel.: +38512310067

E-pošta:darija_dobric@net.hr

\section{Popis pokrata:}

CIC - čista intermitentna kateterizacija

DS - debljina stijenke

ENS - elektrostimulacija

NMD - neuromodulacija

$\mathrm{OAB}$ - engl. overactive bladder

PTNS - perkutana tibijalna neurostimulacija

$\mathrm{RU}$ - rezidualni urin

TENS - transkutana elektrostimulacija

TTNS - transkutana tibijalna neurostimulacija

$\mathrm{V}$ - volumen 


\section{UVOD}

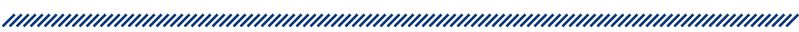

Neurogena disfunkcija mokraćnog mjehura (neurogeni mjehur) nastaje zbog prirođenog ili stečenog oštećenja inervacije donjega mokraćnog sustava. Najčešći su kongenitalni uzroci anomalije kralježnične moždine (mijelomeningokela, lipomeningokela, dijastematomijelija, ageneza sakruma, sindrom kaudalne regresije). Najčešći su stečeni uzroci cerebralna paraliza, transverzalni mijelitis, tumori kralježnične moždine, trauma, progresivne neurodegenerativne bolesti, multipla skleroza, GuillainBarréov sindrom i jatrogeno oštećenje pelvičnog pleksusa. Svaki od ovih uzroka može dovesti do različitog stupnja oštećenja mokraćnog sustava. lako se incidencija prirođenih anomalija kralježnice smanjuje, one i dalje predstavljaju najvažniji uzrok neurogenog mjehura, koji nastaje u oko $95 \%$ ove djece. Ubrzo nakon neurokirurškog zahvata nužno je postaviti ispravnu urodinamsku dijagnozu radi ranog početka liječenja ${ }^{1}$.

Neurogeni mokraćni mjehur koji nastaje uslijed ozljeda leđne moždine i spine bifide ima dubok utjecaj na funkciju pražnjenja².

Postoji više klasifikacija neurogene disfunkcije. Stara podjela na lezije gornjeg i donjeg motornog neurona nije dovoljno precizna jer se kod jednog djeteta mogu naći različite kombinacije aktivnosti detruzora i sfinktera, ovisno o tome u kojoj su mjeri zahvaćena simpatička, parasimpatička i somatska vlakna. Prema van Goolu, urodinamski postoje četiri najčešća podtipa neurogenog mjehura: hiperrefleksija detruzora i hiperrefleksija sfinktera, hiperrefleksija detruzora i hiporefleksija sfinktera, hiporefleksija detruzora i hiperrefleksija sfinktera, hiporefleksija detruzora i sfinktera ${ }^{1}$.

Dijagnostički algoritam uključuje detaljnu anamnezu i fizikalni pregled, neurološki pregled, ultrazvuk bubrega i mokraćnog mjehura, mikcijsku cistouretrografiju, urodinamsko ispitivanje (urodinamiku) i MRI lumbosakralne kralježnice. Kod svakog djeteta s inkontinencijom potrebno je pažljivo pregledati leđa tražeći kožne znakove okultnoga spinalnog dizrafizma (pigmentacija, udubljenje kože, dlaka itd). Pregled uključuje i ispitivanje perinealnog i perianalnog osjeta, tonusa analnog sfinktera, refleksa donjih udova, uključujući bulbokavernozni i anokutani refleks. Urodinamsko ispitivanje (urodinamika) predstavlja zlatni standard u procjeni svih funkcionalnih poremećaja mokraćnog sustava. Zahvaljujući modernim urodinamskih uređajima, da- nas je moguće i bolje razumijevanje patofiziologije neurogenih disfunkcija. S pomoću urodinamskog ispitivanja (urodinamike) određuje se intravezikalni tlak, kapacitet i rastezljivost mjehura, aktivnost detruzora i sfinktera u fazi punjenja i pražnjenja mjehura, tlak kod kojeg nastupa inkontinencija (engl. leak point pressure) i elektromiografija sfinktera. Važno je utvrditi i jesu li funkcije detruzora i vanjskog sfinktera koordinirane. Kontrakcija sfinktera tijekom pražnjenja mokraćnog mjehura naziva se detruzor-sfinkter dissinergija. S pomoću urodinamskih parametara planira se terapijski pristup i procjenjuje rizik oštećenja gornjega mokraćnog sustava. Glavni su čimbenici rizika za oštećenje bubrega niska rastezljivost mjehura, detruzor-sfinkter dissinergija, hiperrefleksija detruzora i jači stupanj deformiteta mjehura. $\mathrm{U}$ djece, osobito u prvoj godini života, postoji tendencija urodinamskim promjenama u pravcu povišenja tlaka detruzora i smanjenja rastezljivosti. Razlog je ovim promjenama u rano dojenačko doba ili kirurška trauma koja dovodi do spinalnog šoka s prolaznom hipoaktivnošću detruzora ili odgovor detruzora na neurogenu infravezikalnu opstrukciju. U kasnijem djetinjstvu nužno je redovito praćenje zbog urodinamskih promjena povezanih s mogućim razvojem sindroma tethered cord, fibrozom sfinktera i malformacijama shunta ${ }^{1}$.

Terapijski pristup znatno se promijenio unazad dvadesetak godina. Glavni je cilj terapije očuvanje bubrežne funkcije, a u školskoj dobi i postizanje kontinencije. Potrebno je što ranije utvrditi faktore rizika za oštećenje gornjeg urotrakta i započeti terapiju prije nego što oštećenje nastane. Osnova je liječenja čista intermitentna kateterizacija. Njome se postiže potpuno pražnjenje mjehura pod niskim tlakom. Osim kateterizacije, primjenjuju se antikolinergici, alfa-adrenergici, kolinergici, simpatikolitici i relaksansi poprečnoprugastih mišića. Kod djece kod koje se konzervativnim putem ne može postići poboljšanje urodinamskog obrasca indicirano je kirurško liječenje (augmentacija i autoaugmentacija mokraćnog mjehura, rekonstrukcija vrata mjehura, apendikovezikostomija, ugradnja umjetnog sfinktera itd. $)^{1}$.

Djeca s neurogenim mjehurom zahtijevaju multidisciplinarni pristup. Ovi pacijenti najčešće imaju i inkontinenciju stolice, neurološke deficite donjih udova, ortopedske anomalije, genitalne probleme, a ponekad i različiti stupanj mentalne retardacije. Stoga je nužno timsko praćenje koje uključuje nefrologa, urologa, neuropedijatra, neurokirurga, ortopeda, gastroenterologa, psihologa, fizijatra, fizioterapeuta i medicinske sestre za edukaciju kateterizacije ${ }^{1}$. 
Neuromodulacija je neinvazivna elektroterapijska metoda primjene električnih stimulansa kako bi se izmijenili trenutačni neurotransmiterski procesi ${ }^{3}$.

Nekoliko je načina primjene ove metode: sakralno površinskim elektrodama u razini od S2 do S4 (TENS), transkutano tibijalno (TTNS), perkutano tibijalno (PTNS) i intravezikalna elektrostimulacija ${ }^{4}$.

Kliničke studije pokazuju uspješnost PTNS-a i sakralne NMD u liječenju prekomjerno aktivnoga mokraćnog mjehura, dok je intravezikalna elektrostimulacija uspješnija kod pacijenata sa spinalnim ozljedama kralježnice ${ }^{5}$.

Nisu poznate komplikacije sakralne $\mathrm{NMD}^{6}$, kao ni utjecaj životne dobi na ishod liječenja?

\section{PRIKAZ SLUČAJA}

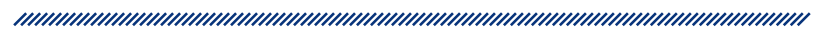

Dječak D. F. u dobi od 6 godina dolazi u našu Polikliniku u listopadu 2015., godinu dana nakon operacije lipo- mijelomeningokele i dermalnog sinusa lumbosakralne regije, nakon koje je došlo do retencije urina (tablica 1 ).

Dijete se od rođenja prati zbog spine bifide occulte. Nije imao ispada motorike donjih ekstremiteta, uredno je kontrolirao mokrenje i stolicu. Urodinamski nalaz prije operacije bio je u granicama normale. Nije bilo infekcija urinarnog sustava (tablica 3,4).

Dijete je s neuromodulacijom započelo u prosincu 2015. godine i provodi je $u$ jednom navratu svaki dan u trajanju od 20 do 30 minuta. Prema preporuci liječnika pedijatra nefrologa, provodio se TTNS prema protokolu.

Već nakon nekoliko provedenih terapija dječak počinje imati osjet mokrenja. Od veljače 2016. godine počinje mokriti spontano, ali je rezidualni urin najviše do $50 \mathrm{ml}$ nakon mokrenja. Nakon mjesec dana terapije počinje osjećati punoću mjehura, a početkom travnja 2016. potpuno osjeća mjehur, nema kapanja urina, pelene su suhe danju i noću. Od tada je potpuno suh, RU nakon mokrenja do $50 \mathrm{ml}$ (tablica 2).

\section{Tablica 1. Prikaz anamnestičkih podataka}

\begin{tabular}{|c|c|}
\hline \multicolumn{2}{|c|}{ Tablica 1. Prikaz anamnestičkih podataka } \\
\hline Ime i prezime: & D. F. \\
\hline Dob: & 6 godina \\
\hline TT i TV & $24,9 \mathrm{~kg}, 127,5 \mathrm{~cm}$ \\
\hline RR & $85 / 60$ \\
\hline Dijagnoza: & stanje nakon operacije lipomijelomenigokele i dermalnog sinusa lumbosakralne regije, \\
unthetering (16. prosinca 2014.), poslijeoperacijska inkontinencija urina
\end{tabular}

\begin{tabular}{|c|c|c|}
\hline Datum: & Uroflow: & Urodinamika: \\
\hline 04/2015. & $\begin{array}{l}10 / 2015 . \mathrm{V}=19 \mathrm{ml}, \mathrm{RU}=40 \mathrm{ml} \\
\text { stijenka nazubljena, neravna }\end{array}$ & Nađeni visoki tlakovi u fazi punjenja, uvedena je $\mathrm{CIC} 4$ x dnevno \\
\hline $11 / 2015$ & $\begin{aligned} \mathrm{V} & =13 \mathrm{ml} \\
\mathrm{RU} & =80 \mathrm{ml}\end{aligned}$ & $\begin{array}{l}\text { U fazi punjenja mokraćnog mjehura nema osjet, kapacitet oko } 103 \mathrm{ml} \text {. Mokri pod } \\
\text { tlakom od } 60 \text { do } 63 \mathrm{cmH}_{2} 0 \text {. Ne može relaksirati sfinkter, RU obilan, oko } 105 \mathrm{ml} \text {. }\end{array}$ \\
\hline $03 / 2016$ & $\begin{array}{l}\mathrm{V}=88 \mathrm{ml} \\
\mathrm{RU}=59 \mathrm{ml} \\
\mathrm{DS}=2,6 \mathrm{~mm}\end{array}$ & $\begin{array}{l}\text { U fazi punjenja mokraćnog mjehura ima osjet, kapacitet oko } 108 \mathrm{ml} \text {. Mokri pod } \\
\text { tlakom od oko } 60 \text { do } 64 \mathrm{cmH}_{2} 0 \text {. Ne može relaksirati sfinkter, } \mathrm{RU} \text { prisutan. }\end{array}$ \\
\hline 09/2016. & $\begin{array}{c}\mathrm{V}=55 \mathrm{ml} \\
\mathrm{RU}=27 \mathrm{ml} \\
\mathrm{DS}=2,8 \mathrm{~mm}\end{array}$ & $\begin{array}{l}\text { U fazi punjenja mokraćnog mjehura ima osjet, od } 82 \mathrm{ml} \text { počinju se javljati } \\
\text { neinhibirane kontrakcije detruzora maks. do } 49 \mathrm{cmH}_{2} 0 \text { kod } 172 \mathrm{ml} \text {. Kapacitet oko } \\
173 \mathrm{ml} \text {. Mokri pod tlakom od oko } 60 \mathrm{cmH}_{2} 0 . \mathrm{RU} \text { prisutan. Nalaz u poboljšanju. }\end{array}$ \\
\hline 02/2017. & $\begin{aligned} \mathrm{V} & =63 \mathrm{ml} \\
\mathrm{RU} & =74 \mathrm{ml} \\
\mathrm{DS} & =3,3 \mathrm{~mm}\end{aligned}$ & $\begin{array}{l}\text { U fazi punjenja mokraćnog mjehura ima osjet, nema više neinhibiranih } \\
\text { kontrakcija detruzora. Kapacitet oko } 255 \mathrm{ml} \text {. Mokri pod tlakom od oko } 73 \mathrm{cmH}_{2} 0 \text {. } \\
\text { RU prisutan. Nalaz i dalje u poboljšanju, osim prisutnog RU-a. }\end{array}$ \\
\hline
\end{tabular}




\begin{tabular}{|c|c|}
\hline \multicolumn{2}{|c|}{ Tablica 3. Funkcionalna procjena - mokraća } \\
\hline Dnevnik mokrenja: & 17. svibnja 2017. \\
\hline Najmanja/najveća vrijednost: & $20 \mathrm{ml} / 120 \mathrm{ml}$ \\
\hline Frekvencija: & 8 do 9 puta dnevno \\
\hline Jutarnje porcije urina: & 20 do $90 \mathrm{ml}$ \\
\hline Bijeg urina: & $/$ \\
\hline Unos tekućine: & $1000 \mathrm{ml}$ \\
\hline
\end{tabular}

\section{RASPRAVA}

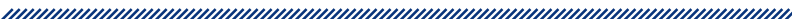

O učinku neuromodulacije govore brojne studije. Sakralna neuromodulacija ima ogroman utjecaj na liječenje urinarne inkontinencije i simptoma donjega mokraćnog trakta kod bolesnika s neurološkim oboljenjima, osobito neurogenim mjehurom ${ }^{8}$.

Neinvazivne i invazivne modifikacije elektrostimulacije (ENS) za disfunkciju crijeva i mjehura proučavane su i odobrene u djece. Postupak uključuje transkutanu elektrostimulaciju živca, intravezikalnu elektrostimulaciju živca, perkutanu stimulaciju tibijalnog živca i sakralnu neuromodulaciju kod različitih stanja, uključujući prekomjerno aktivni mokraćni mjehur, enurezu, disfunkcijsko mokrenje, zatvor, kombiniranu disfunkciju mokraćnog mjehura, neurogeni mjehur i disfunkciju crijeva. Visokokvalitetna randomizirana ispitivanja s dugoročnim rezultatima mogla bi odgovoriti na pitanje je li ENS sposoban dugoročno mijenjati ishod bolesti za dijete s obostranom disfunkcijom crijeva i mjehura ${ }^{9}$.

TTNS je djelotvoran i dobro podnošljiv tretman kod bolesnika s inkontinencijom hitnosti kao terapija prvog reda i trebao bi se ponuditi kao rana intervencija u strategiji liječenja. Nove su studije potrebne za identifikaciju optimalnih parametara stimulacije, najučinkovitijih protokola liječenja i dugotrajne učinkovitosti, kao i njezinu primjenjivost na pacijente $s$ neurogenim supstratom ${ }^{10}$.

Ova metoda liječenja upotrebljava se u liječenju neneurogenog prekomjerno aktivnoga mokraćnog mjehura u djece. S obzirom na njegovu učinkovitost i prihvatljivost, vjeruje se da bi TTNS trebao biti dio smjernica dječje urologije za liječenje OAB-a ${ }^{11}$.

Nekirurško liječenje pacijenata sa spinom bifidom temelji se na održavanju kompatibilnog mjehura adekvatne veličine, što može spriječiti progresivno oštećenje mjehura i trajnu promjenu gornjeg dijela urotrakta s oštećenjem bubrega i mogućim renalnim zatajenjem ${ }^{12}$.
Tablica 4. Funkcionalna procjena - stolica

\begin{tabular}{|c|c|}
\hline Redovitost: & jednom dnevno \\
\hline Konzistencija: & mekana \\
\hline Veličina: & normalna \\
\hline Bristolska skala stolice: & Type 4 \\
\hline Bjegovi stolice: & ne \\
\hline Količina stolice: & $/$ \\
\hline Broj bjegova: & $/$ \\
\hline
\end{tabular}

\section{ZAKLJUČAK}

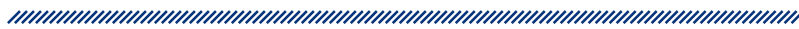

Dijagnoza neurogenoga mokraćnog mjehura zahtijeva multidisciplinarni pristup u svrhu postizanja što bolje kvalitete života djeteta. Neuromodulacija kao oblik terapijskog liječenja ima dokazanu pozitivnu učinkovitost kod brojnih poremećaja mokrenja, ne zahtijeva posebnu pripremu djeteta, jednostavna je za primjenu u djece, a rezultati ovise individualno o svakom djetetu $i$ vidljivi su nakon četiri do osam tjedana primjene. 


\section{LITERATURA}

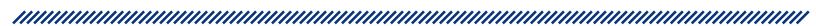

1. Cvitković Roić A. Neurogeni mokraćni mjehur [internet]. Zagreb: Poliklinika za dječje bolesti Helena; 2017. Dostupno na: http://www.poliklinika-helena.hr/zanimljivo-izpedijatrije/pedijatrijska-nefrologija-i-urologija/neurogeni-mokracni-mjehur (pristupljeno 15.9.2017.).

2. Burks FN, Bui DT, Peters KM. Neuromodulation and the neurogenic bladder. Urol Clin North Am. 2010; 37(4): 559-565.

3. Chancellor MB, Chartier-KastlerEJ. Principles of Sacral Nerve Stimulation (SNS) for the Treatment of Bladder and Urethral Sphincter Dysfunctions. Neuromodulation. 2000; 3(1): 16-26. doi: https://doi.org/10.1046/j.1525-1403.2000.00015.x

4. Abrams P, Blaivas JG, Fowler CJ, Fourcroy JL, Macdiarmid SA, Siegel SW, et al. The role of neuromodulation in the management of urinary urge incontinence. BJU Int. 2003; 91(4): 355-359.

5. Janssen DA, Martens FM, de Wall LL, van Breda HM, Heesakkers JP. Clinical utility of neurostimulation devices in the treatment of overactive bladder: current perspectives. Med Devices (Auckl). 2017; 10: 109-122.

6. Fuchs ME, Lu PL, Vyrostek SJ, Teich S, Alpert SA. Factors Predicting Complications After Sacral Neuromodulation in Children. Urology. 2017; 107: 214-217. doi: https://doi. org/10.1016/j.urology.2017.05.014
7. Faris AER, Gill BC, Pizarro-Berdichevsky J, Dielubanza $\mathrm{E}$, Clifton MM, Okafor $\mathrm{H}$, et al. Impact of Age and Comorbidities on Use of Sacral Neuromodulation. J Urol. 2017; 198(1): 161-166. doi: https://doi.org/10.1016/j.juro.2017.02.020

8. Powell CR. Conditional Electrical Stimulation in Animal and Human Models for Neurogenic Bladder: Working Toward a Neuroprosthesis. Curr Bladder Dysfunct Rep. 2016; 11(4): 379-385.

9. Wright AJ, Haddad M. Electroneurostimulation for the management of bladder bowel dysfunction in childhood. Eur J Paediatr Neurol. 2017; 21(1): 67-74. doi: https:// doi.org/10.1016/j.ejpn.2016.05.012

10. Valles-Antuña C, Pérez-Haro ML, González-Ruiz de L C, Quintás-Blanco A, Tamargo-Diaz EM, García-Rodríguez J, et al. Transcutaneous stimulation of the posterior tibial nerve for treating refractory urge incontinence of idiopathic and neurogenic origin. Actas Urol Esp. 2017; 41(7): 465470. doi: https://doi.org/10.1016/j.acuro.2017.01.009

11. Patidar N, Mittal V, Kumar M, Sureka SK, Arora S, Ansari MS. Transcutaneous posterior tibial nerve stimulation in pediatric overactive bladder: A preliminary report. $J$ Pediatr Urol. 2015; 11(6): 351.e1-351.e6. doi: https://doi. org/10.1016/j.jpurol.2015.04.040

12. Carr MC. Conservative Nonsurgical Management of Spina Bifida. Curr Urol Rep. 2010; 11(2): 109-113. doi: https://doi. org/10.1007/s11934-010-0096-6 


\section{NEUROMODULATION AS A TREATMENT OF CHOICE FOR A CHILD WITH NEUROGENIC BLADDER - CASE REPORT}

\section{Abstract}

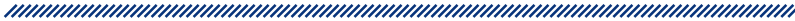

Introduction. Neurogenic bladder occurs due to an inherent or acquired impairment of the lower urinary tract. Although the incidence of spinal abnormalities is decreasing, it continues to be the leading cause of neurogenic bladder occurring in approximately 95\% of children with this impairment. Neuromodulation as a physiotherapeutic intervention has a significant role in the rehabilitation of children with neurogenic bladder.

The aim of this paper was to present the case of a child with neurogenic bladder due to spina bifida and the possibilities of neuromodulation rehabilitation therapy.

Elaboration. The study presents the case of a child with neurogenic bladder as a consequence of spina bifida where retention of urine occurred after surgical treatment. A specific initial physiotherapeutic assessment showed a decreased amount of urine with incomplete discharge, loss of bladder fullness sensation and urine loss during the day and night. Physiotherapeutic intervention included neuromodulation each day according to the default protocol for 20-30 min. The child's parents were educated about continuing home-based therapy with the purchased device.

Conclusion. Neurogenic bladder requires a multidisciplinary approach to achieve the best quality of life for a child. Neuromodulation as a form of therapeutic treatment is a simple method which has proven to have a positive effect in many urinary disorders; it does not require special preparation of the child, it is a simple method, the results depend on each child individually.
Keywords: neurogenic bladder, neuromodulation, physiotherapy 